Check for updates

Cite this: RSC Adv., 2017, 7, 32601

\title{
A biomimetic ion-crosslinked layered double hydroxide/alginate hybrid film $\uparrow$
}

\author{
Ben-liang Liang, Jian-feng Wang, ${ }^{*}$ Ying-qi Shu, Peng-gang Yin (D) * and Lin Guo \\ Natural nacre has an ordered layered arrangement of calcium carbonate platelets and ion-crosslinked \\ protein, which enable it to achieve outstanding mechanical properties. Inspired by the relationship \\ between structure and mechanical properties of natural nacre, we fabricate a $\mathrm{Ca}^{2+}$-crosslinked layered \\ double hydroxide/alginate (LDH/ALG-Ca ${ }^{2+}$ ) hybrid film through filtration of $\mathrm{Ca}^{2+}$-crosslinked LDH/ALG \\ hybrid building blocks. The LDH nanoplatelets and alginate were alternately stacked giving an ordered \\ layered structure, in which alginate was crosslinked by $\mathrm{Ca}^{2+}$. The effect of LDH content and $\mathrm{Ca}^{2+}$ \\ crosslinking on the microstructure and interfacial interaction of LDH/ALG-Ca ${ }^{2+}$ hybrid films was studied \\ systematically. The optimized nacre-like hybrid film exhibits good flexibility and high strength (194 MPa), \\ superior to natural nacre. The ordered layered structure and small diameter of LDH give the hybrid film \\ a high transparency of $74-94 \%$ in the visible light wavelength range.
}

Received 24th April 2017 Accepted 20th June 2017

DOI: 10.1039/c7ra04577h

rsc.li/rsc-advances composites. ${ }^{12}$ Interfacial hydrogen bond, ionic bond and covalent bond are usually designed and complemented to improve stress transfer efficiency at interface. ${ }^{\mathbf{1 1 , 1 2 , 4 7 - 5 1}}$ In addition, the strength of organic matrices themselves is also important and can be enhanced through chemical or physical crosslinking. ${ }^{30}$ However, relative to large-size inorganic nanoplatelets (montmorillonite, graphene oxide, alumina typically has diameter more than $1 \mu \mathrm{m})$, small-size inorganic nanoplatelets with diameter less than $100 \mathrm{~nm}$ are rarely used to construct nacremimetic materials.

In this work, we choose small-size $\mathrm{Ni}-\mathrm{Al}-\mathrm{NO}_{3}$ layered double hydroxide (LDH) with a diameter of about $70 \mathrm{~nm}$ as inorganic nanoplatelets and sodium alginate (ALG) as organic component to construct nacre-mimetic layered composites with high transparency. The $\mathrm{Ni}-\mathrm{Al}-\mathrm{NO}_{3} \mathrm{LDH}$ with positive charge on surface would interact with ALG through electrostatic and hydrogen-bonding interaction. Divalent calcium ion is introduced to strengthen ALG matrix through ionic crosslinking with the G units of ALG, forming "egg-box" structure. ${ }^{52-55}$ The effect of oriented arrangement of $\mathrm{LDH}$, ionic crosslinking of ALG and interfacial interaction between $\mathrm{LDH}$ and ALG on the mechanical properties of hybrid film are studied. The resultant nacre-mimetic hybrid film has tensile strength as high as $194 \mathrm{MPa}$ and excellent flexibility. In addition, the hybrid film exhibits high transparency because small size of $\mathrm{LDH}$ with diameter much less than visible light wavelength (400-900 $\mathrm{nm}$ ) decreases light scattering. It is expected that the strong, flexible and transparent layered composite film has the potential as optical functional materials for a variety of applications, such as substrates for flexible displays, components for precision optical devices, windows for automobile and trains.
School of Chemistry and Environment, Beihang University, Beiji
China. E-mail: wangjianfeng@buaa.edu.cn; pgyin@buaa.edu.cn

$\dagger$ Electronic supplementary information (ESI) available. See DOI: 10.1039/c7ra04577h 


\section{Experimental section}

\subsection{Materials}

ALG was purchased from Guangdong Guanghua Chemical Factory Co. Ltd. $\mathrm{Ni}\left(\mathrm{NO}_{3}\right)_{2} \cdot 6 \mathrm{H}_{2} \mathrm{O}, \mathrm{Al}\left(\mathrm{NO}_{3}\right)_{3} \cdot 9 \mathrm{H}_{2} \mathrm{O}$ and $\mathrm{NaOH}$ were purchased from Sinopharm Chemical Reagent Co. Ltd. Anhydrous $\mathrm{CaCl}_{2}$ was purchased from Tianjin Jinke Fine Chemical Research Institute. All materials were used as received. Polyamide filtration membrane ( $220 \mathrm{~nm}$ pore size) was purchased from Shanghai Xinya.

\subsection{Fabrication of LDH/ALG-Ca ${ }^{2+}$ hybrid film}

The fabrication process for $\mathrm{LDH} / \mathrm{ALG}-\mathrm{Ca}^{2+}$ artificial nacre is illustrated in Scheme 1. The Ni-Al- $\mathrm{NO}_{3} \mathrm{LDH}$ powder was synthesized by the method that has been reported in our previous work. ${ }^{\mathbf{4 1 , 5 6}}$ The synthesized LDH powder $(0.1 \mathrm{~g})$ was exfoliated in formamide $(100 \mathrm{ml})$ by vigorously agitating for $24 \mathrm{~h}$ under $\mathrm{N}_{2}$ gas flow. The exfoliated $\mathrm{LDH}$ was mixed with a required amount of ALG solution with a concentration of 0.1 $\mathrm{wt} \%$, forming a homogeneous dispersion. Then, a required amount of $\mathrm{CaCl}_{2}$ aqueous solution with a concentration of 0.1 wt\% was gradually instilled into the homogeneous dispersion and continually stirred for about $3 \mathrm{~h}$, forming LDH/ALG-Ca ${ }^{2+}$ hybrid building blocks. The obtained mixture was filtrated under vacuum through polyamide filtration membrane, and dried under room temperature, leading to a transparent $\mathrm{LDH} /$ ALG-Ca ${ }^{2+}$ hybrid film. In the hybrid film, LDH contents was controlled by adjusting the mixing volume ratios of $\mathrm{LDH}$ dispersion to ALG aqueous solution. $\mathrm{Ca}^{2+}$ content relative to ALG was altered by adjusting the mixing volume ratio of $\mathrm{CaCl}_{2}$ solution to ALG solution (ESI, Table S1 $\dagger$ ).

\subsection{Characterization}

X-ray diffraction (XRD) was recorded by a Shimadzu XRD-6000 diffractometer under the following conditions: $40 \mathrm{kV}, 40 \mathrm{~mA}$ and $\mathrm{Cu} \mathrm{K}_{\alpha}$ radiation. Fourier transform infrared (FTIR) spectra

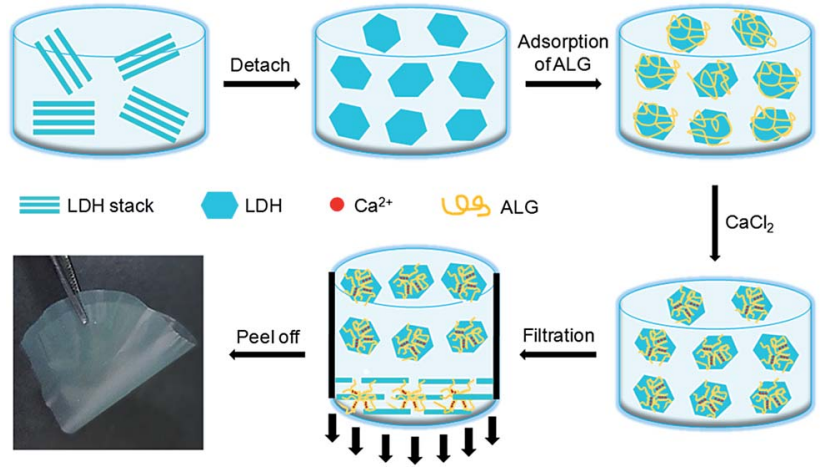

Scheme 1 Fabrication process for LDH/ALG-Ca ${ }^{2+}$ hybrid film. The synthesized $\mathrm{Ni}-\mathrm{Al}-\mathrm{NO}_{3} \mathrm{LDH}$ stacks are exfoliated mechanically, followed by mixing with ALG solution to form ALG-coated LDH. Then, the ALG-coated LDH is further crosslinked with $\mathrm{Ca}^{2+}$, leading to LDH/ ALG-Ca ${ }^{2+}$ hybrid building blocks. Finally, the hybrid building blocks are assembled into transparent LDH/ALG-Ca ${ }^{2+}$ hybrid film through filtration. were conducted on an iN10MX FTIR instrument with the attenuated total reflection mode (ATR). Dynamic light scattering measurements and zeta potential tests were carried out on Malvern Zetasizer Nano ZS90. The light transmittance spectra were recorded in the range from 400 to $900 \mathrm{~nm}$ on a Shimadzu-3600 spectrophotometer. Scanning electron microscopy (SEM) was performed on a JEOL JSM7500FA field emission microscope. Tensile mechanical properties were tested using a Shimadzu AGS-X at a loading speed of $1 \mathrm{~mm}$ $\mathrm{min}^{-1}$ with a gauge length of $5 \mathrm{~mm}$. All samples were cut into 10 $\mathrm{mm}$ in length and $3 \mathrm{~mm}$ in width.

\section{Results and discussion}

The synthesized $\mathrm{Ni}-\mathrm{Al}-\mathrm{NO}_{3} \mathrm{LDH}$ was exfoliated through mechanical stirring, generating single-layer $\mathrm{LDH}$ nanoplatelets with positive charge on surface (ESI, Fig. S1 $\dagger$ ). The exfoliated LDH platelets have a diameter of about $70 \mathrm{~nm}$ and a thickness of about $0.9 \mathrm{~nm}$, as measured by TEM and AFM (ESI, Fig. S2 $\dagger$ ). After mixed with ALG solution, the positively charged LDH nanoplatelets were coated by negatively charged ALG because of electrostatic and hydrogen-bonding interactions. Considering that ALG, a well known ionic polysaccharide, can chelate with divalent cations to form the "egg-box" structure. ${ }^{54,57}$ We use $\mathrm{Ca}^{2+}$ to crosslink ALG on the surface of $\mathrm{LDH}$, forming $\mathrm{LDH} / \mathrm{ALG}-\mathrm{Ca}^{2+}$ hybrid building blocks. The hybrid building blocks were further processed into film through vacuum-assisted filtration. The ionic crosslinking would strengthen ALG and thus help to improve mechanical strength of hybrid film. ${ }^{17}$ After drying, the film was peeled from filtration membrane, leading to transparent, flexible and glossy LDH/ALG-Ca ${ }^{2+}$ hybrid film (Scheme 1).

\subsection{Microstructure of LDH/ALG-Ca ${ }^{2+}$ hybrid film}

To investigate the effect of $\mathrm{LDH}$ content on microstructure, six LDH/ALG-Ca ${ }^{2+}$ hybrid films with different LDH contents $(5 \%$, $10 \%, 20 \%, 30 \%, 40 \%, 50 \%)$ and constant mixing mass ratio of $\mathrm{CaCl}_{2}$ to ALG (0.5) were prepared. The microstructure of these hybrid films was examined by SEM, as shown in Fig. 1. For low LDH content (5\%), it can be observed that the $\mathrm{LDH}$ platelets are
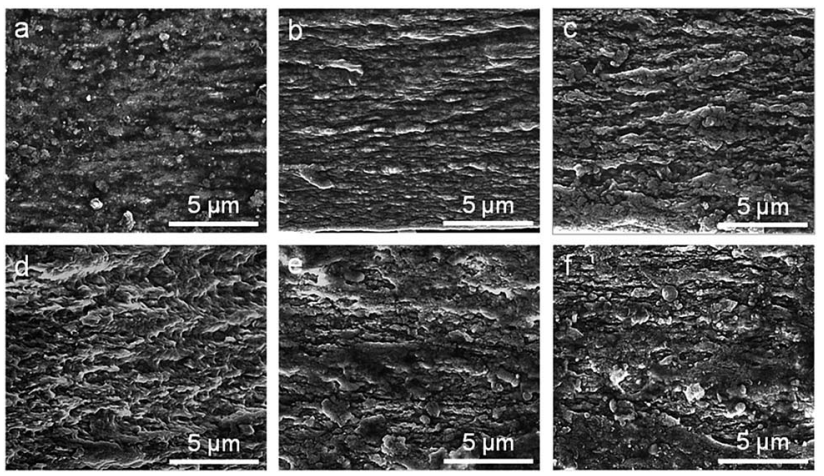

Fig. 1 Cross-sectional SEM images of LDH/ALG-Ca ${ }^{2+}$ hybrid films with different LDH contents. (a) $5 \%$, (b) $10 \%$, (c) $20 \%$, (d) $30 \%$, (e) $40 \%$, (f) $50 \%$. 
homogeneously embedded into the ALG matrix without oriented arrangement (Fig. 1a). Differently, a layered structure appears when the LDH concentration is $10 \%$ (Fig. 1b). The sheet-like layers are parallel to the film surface and interpenetrated into adjacent layers, similar to previously reported nacre-mimetic hybrid films based on large-size inorganic platelets (clay, ${ }^{13,16,48} \mathrm{GO},{ }^{36,44,58} \mathrm{Al}_{2} \mathrm{O}_{3}$ (ref. 29, 31 and 59)). The full EDX spectrum of the cross section exhibits the signals originating from ALG (carbon and oxygen), LDH (nickel, aluminium) and calcium chloride (calcium) (ESI, Fig. S3 $\dagger$ ). These elements are uniformly distributed within the hybrid films, as proved by element mapping. However, when the LDH concentration is $20 \%$ or more, the layered structure disappears and is transformed to LDH aggregation (Fig. 1c-f). This is possibly attributed to the fact that high content of LDH nanoplatelets cannot be sufficiently covered by $\mathrm{Ca}^{2+}$-crosslinked ALG molecules. ${ }^{16}$ Thus, a part of bare LDH nanoplatelets aggregate together, leading to random distribution. The aggregation is also evidenced by X-ray diffraction (ESI, Fig. S4 $\dagger$ ). When the content of $\mathrm{LDH}$ is $20 \%$ or more, the diffraction peak position is the same as that of pure $\mathrm{LDH}$. The aggregation is also reflected by dynamic light scattering measurement, which is carried out for $\mathrm{LDH} / \mathrm{ALG} / \mathrm{CaCl}_{2}$ solutions before filtration (ESI, Fig. S5 $\dagger$ ). For the mixing solution with high $\mathrm{LDH}$ content relative to ALG, the hydrodynamic diameter is obviously larger than those of exfoliated LDH dispersion and ALG solution.

In order to investigate the effect of $\mathrm{Ca}^{2+}$ on microstructure, four $\mathrm{LDH} / \mathrm{ALG}-\mathrm{Ca}^{2+}$ hybrid film with different $\mathrm{Ca}^{2+}$ contents and constant $\mathrm{LDH}$ content of $10 \%$ were prepared. The effect of $\mathrm{Ca}^{2+}$ on the microstructure of hybrid films was examined by SEM, as shown in Fig. 2. For low ratio of $\mathrm{CaCl}_{2}$ to $\mathrm{ALG}(0.25,0.5)$, the LDH/ALG-Ca ${ }^{2+}$ hybrid building blocks form a distinct layered structure, like that of natural nacre. Differently, when the mixing mass ratio of $\mathrm{CaCl}_{2}$ to ALG surpasses 0.5 , the structure of LDH/ALG-Ca ${ }^{2+}$ hybrid film transforms from nacre-like layered arrangement to $\mathrm{LDH}$ aggregation. Such structure change is
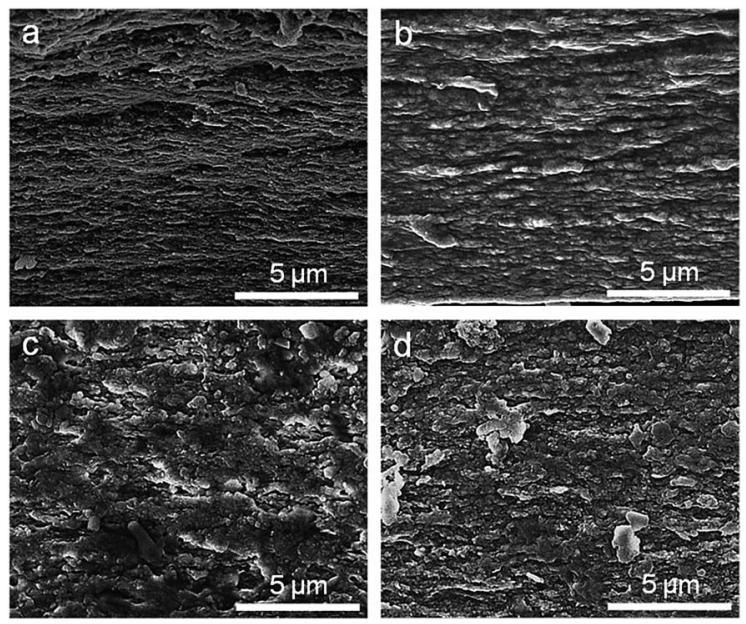

Fig. 2 Cross-sectional SEM images of LDH/ALG-Ca ${ }^{2+}$ hybrid film with different mixing mass ratio of $\mathrm{CaCl}_{2}$ to ALG. (a) 0.25 , (b) 0.5 , (c) 1 , (d) 2 . For low mass ratio $(0.25,0.5)$, a layered structure are observed. For high mass ratio $(1,2)$, the structure is transformed to $\mathrm{LDH}$ aggregation. probably attributed to the fact that $\mathrm{Ca}^{2+}$ crosslinking affects the absorption of ALG on the surface of LDH nanoplatelets. $\mathrm{Ca}^{2+}$ crosslinked ALG has an "egg-box" structure, which increase the stiffness of ALG molecule chains and change their spatial configuration..$^{5,57,60}$ The stiffening ALG at high $\mathrm{Ca}^{2+}$ content cannot sufficiently absorb onto the surface of $\mathrm{LDH}$ nanoplatelets, generating a part of bare $\mathrm{LDH}$ nanoplatelets. The insufficient absorption would decrease hydrogen bond and electrostatic interaction between ALG and $\mathrm{LDH}$. As a result, these bare LDH nanoplatelets would aggregate together. The aggregation is also proved by X-ray diffraction, as shown in ESI, Fig. S6. $\uparrow$ When the mixing mass ratio of $\mathrm{CaCl}_{2}$ to ALG is 1 or 2 , the diffraction peak position is the same as that of pure LDH. The aggregation is also reflected by dynamic light scattering measurement, which is carried out for $\mathrm{LDH} / \mathrm{ALG} / \mathrm{CaCl}_{2}$ solutions before filtration (ESI, Fig. S7 $\dagger$ ). For the mixing solution with high mixing mass ratio of $\mathrm{CaCl}_{2}$ to $\mathrm{ALG}$, the hydrodynamic diameter is obviously larger than those of exfoliated LDH dispersion and ALG solution.

\subsection{Ionic crosslinking and interfacial interaction}

The interfacial hydrogen bond and electrostatic interaction between LDH and ALG was proved by FTIR spectra, as shown in Fig. 3a. Pure ALG exhibits $\mathrm{O}-\mathrm{H}$ stretching vibration in the wavenumber range of $3100-3600 \mathrm{~cm}^{-1}$ and $\mathrm{C}=\mathrm{O}$ stretching vibration at $1751 \mathrm{~cm}^{-1}$. Pure $\mathrm{Ni}-\mathrm{Al}-\mathrm{NO}_{3} \mathrm{LDH}$ exhibits $\mathrm{O}-\mathrm{H}$ stretching vibration in the wavenumber range of 3100-3600 $\mathrm{cm}^{-1}$, interlayer water absorption peak at $1648 \mathrm{~cm}^{-1}$ and $\mathrm{NO}_{3}{ }^{-}$ feature peak at $1353 \mathrm{~cm}^{-1}$. For LDH/ALG-Ca ${ }^{2+}$ hybrid film, the $\mathrm{O}-\mathrm{H}$ stretching vibration is suppressed, due to the formation of hydrogen bond network between LDH and ALG. ${ }^{\mathbf{1 3 , 4 4}}$ Because the negatively charged ALG, instead of $\mathrm{NO}_{3}{ }^{-}$and interlayer water, coats positively charged $\mathrm{LDH}$, the absorption peak of interlayer water and $\mathrm{NO}_{3}{ }^{-}$disappears. ${ }^{56}$ In addition, the $\mathrm{C}=\mathrm{O}$ stretching vibration at $1751 \mathrm{~cm}^{-1}$ was weakened, and a new $\mathrm{C}=\mathrm{O}$ stretching vibration peak at $1686 \mathrm{~cm}^{-1}$ appears. This is due to that the carboxyl groups in M units of ALG form hydrogen bond with the hydroxyl groups on the surface of $\mathrm{LDH}$, while the carboxyl groups in $\mathrm{G}$ units of ALG are crosslinked by $\mathrm{Ca}^{2+}$, stiffen and cannot form hydrogen bond with LDH (ESI, Fig. S8 and S9†). ${ }^{\mathbf{2}}$

The effect of $\mathrm{Ca}^{2+}$ crosslinking on interfacial hydrogen bond between LDH and ALG was investigated by FTIR spectra, as shown in Fig. 3b. At low ratio of $\mathrm{CaCl}_{2}$ to $\operatorname{ALG}(0.25,0.5)$,
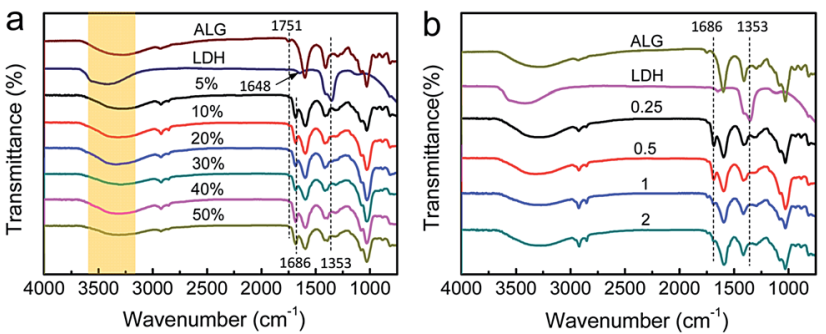

Fig. 3 FTIR spectra of LDH/ALG-Ca ${ }^{2+}$ hybrid films. (a) Hybrid films with different $\mathrm{LDH}$ content and constant mass ratio of $\mathrm{CaCl}_{2}$ to ALG (0.5). (b) Hybrid films with constant LDH content (10\%) and different mass ratio of $\mathrm{CaCl}_{2}$ to $\mathrm{ALG}$. 
interfacial hydrogen bond interaction induces the $\mathrm{C}=\mathrm{O}$ stretching vibration of ALG to divide into two peaks, locating at 1751 and $1686 \mathrm{~cm}^{-1}$. At high ratio of $\mathrm{CaCl}_{2}$ to $\operatorname{ALG}(1,2)$, the $\mathrm{C}=\mathrm{O}$ stretching vibration peak at $1686 \mathrm{~cm}^{-1}$ obviously became weak. ${ }^{17,54}$ It suggests that $\mathrm{Ca}^{2+}$ crosslinks ALG for reinforcement at the cost of the decrease of hydrogen bond interaction between LDH and ALG. It is probably due to that overmuch $\mathrm{Ca}^{2+}$ crosslinking sharply increases the rigidness of ALG molecular chains, and thus impedes hydrogen bond formation between $\mathrm{LDH}$ and $\mathrm{M}$ units of ALG. ${ }^{35} \mathrm{So}$, the mixing mass ratio of $\mathrm{CaCl}_{2}$ to ALG has a optimal value of 0.5 , at which ionic crosslinking of ALG by $\mathrm{Ca}^{2+}$ and interfacial hydrogen bond between LDH and ALG is finely balanced.

\subsection{Properties of LDH/ALG-Ca ${ }^{2+}$ hybrid film}

3.3.1. Mechanical property. The tensile properties of LDH/ ALG-Ca ${ }^{2+}$ hybrid films with different LDH contents and constant mass ratio of $\mathrm{CaCl}_{2}$ to ALG (0.5) were measured to relate microstructure with mechanical property (Fig. $4 \mathrm{a}$ and b). In the range of $0-10 \%$, the tensile strength sharply increases from $84 \mathrm{MPa}$ for $5 \% \mathrm{LDH} / \mathrm{ALG}-\mathrm{Ca}^{2+}$ to $194 \mathrm{MPa}$ for $10 \% \mathrm{LDH} / \mathrm{ALG}-\mathrm{Ca}^{2+}$. In this content range, ALG molecules are easily coated onto exfoliated LDH nanosheets to form hybrid building blocks by strong electrostatic and hydrogen bond interactions. The microstructure of hybrid films transforms from random distribution for $5 \% \mathrm{LDH} /$ $\mathrm{ALG}^{-\mathrm{Ca}^{2+}}$ to nacre-like layered arrangement for $10 \% \mathrm{LDH} / \mathrm{ALG}-$ $\mathrm{Ca}^{2+}$, which leads to the dramatic increase of tensile strength. When LDH content is higher than $20 \%$, a part of LDH nanoplatelets start to aggregate together and the layered structure disappears, which deteriorate tensile strength.

The tensile properties of LDH/ALG- $\mathrm{Ca}^{2+}$ hybrid films with different mixing mass ratio of $\mathrm{CaCl}_{2}$ to ALG and constant $\mathrm{LDH}$
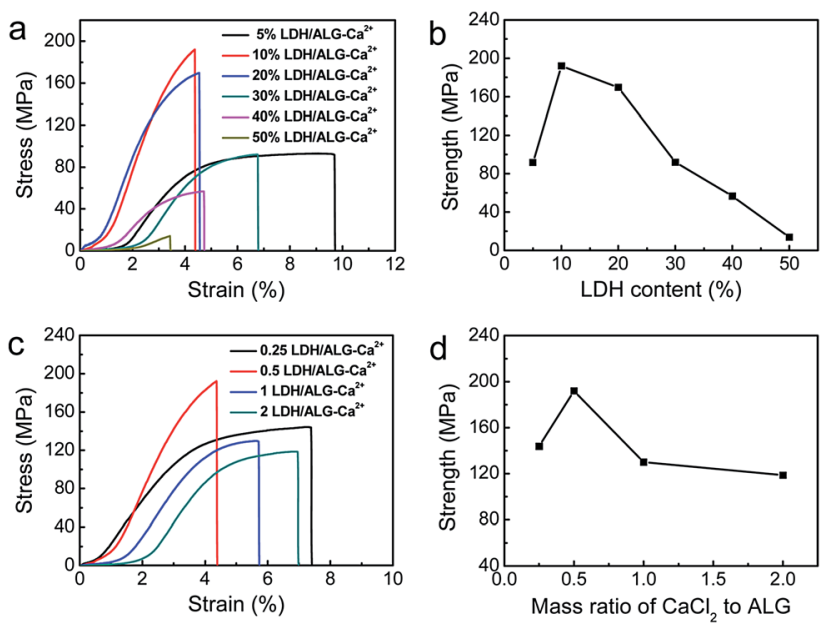

Fig. 4 Mechanical properties of LDH/ALG-Ca ${ }^{2+}$ hybrid films. (a) Representative tensile stress-strain curves of the hybrid films with different LDH content. (b) The effect of LDH content on tensile strength of hybrid films, showing a maximum strength at $10 \% \mathrm{LDH}$. (c) Representative tensile stress-strain curves of the hybrid film with different mass ratio of $\mathrm{CaCl}_{2}$ to $A L G$. (d) The effect of the mass ratio of ALG to $\mathrm{CaCl}_{2}$ on tensile strength of hybrid films, showing a maximum strength at mass ratio of 0.5 .
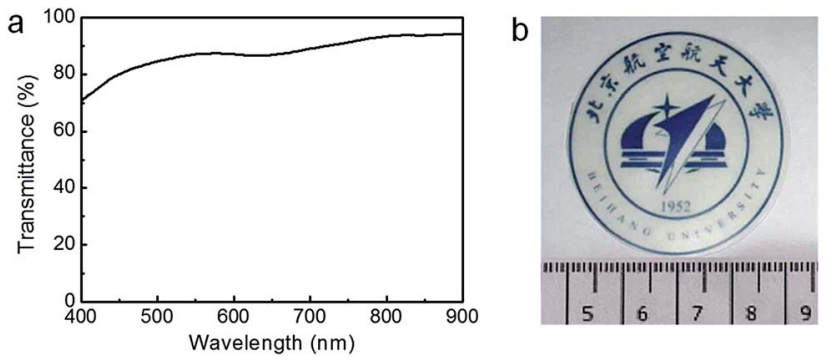

Fig. 5 (a) Light transmittances and (b) photograph of 10\% LDH/ALG$\mathrm{Ca}^{2+}$ hybrid films. The thicknesses of film is about $20 \mu \mathrm{m}$.

content $(10 \%)$ were measured to relate interfacial interaction with mechanical property (Fig. $4 \mathrm{c}$ and d). In general, $\mathrm{Ca}^{2+}$ crosslinking can increase the strength of ALG (ESI, Fig. S10†). When the mass ratio of $\mathrm{CaCl}_{2}$ to ALG increases from 0.25 to 0.5 , $\mathrm{Ca}^{2+}$ crosslinking does not obviously weaken the hydrogen bond interaction between ALG and LDH. The synergism of hydrogen bonds and ionic crosslinking results in the increase of tensile strength from $142 \mathrm{MPa}$ to $194 \mathrm{MPa}$. However, with further increase of the mass ratio of $\mathrm{CaCl}_{2}$ to ALG, the tensile strength decrease obviously. Although more $\mathrm{Ca}^{2+}$ strengths ALG through ionic crosslinking, the interfacial hydrogen bond interaction between LDH and ALG is weakened with a part of LDH nanoplatelets being aggregated together.

According to above-mentioned analysis, it can be found that layered structure, moderate ionic crosslinking of ALG by $\mathrm{Ca}^{2+}$ and plenty of hydrogen bond between LDH and ALG are the key to achieve high-strength LDH/ALG-Ca ${ }^{2+}$ hybrid films. $10 \% \mathrm{LDH} /$ ALG-Ca ${ }^{2+}$ with mass ratio of $\mathrm{CaCl}_{2}$ to ALG being 0.5 meets all of these conditions and generate optimal synergism, leading to highest tensile strength of $194 \mathrm{MPa}, 1.5$ times higher than natural nacre (tensile strength of 80-135 MPa). ${ }^{7}$ Furthermore, the hybrid film is flexible and can be folded without risk of fracture.

3.3.2. Transparency. The nacre-mimetic LDH/ALG-Ca ${ }^{2+}$ hybrid film has high optical transparency, as shown in Fig. 5. In visible light wavelength range of 400 to $900 \mathrm{~nm}$, the light transmittance is $70-94 \%$, obviously higher than previously reported layered montmorillonite/chitosan hybrid film (60-80\%) with similar thickness. ${ }^{21}$ The high optical transparency is mainly attributed to two reasons: small size of LDH nanoplatelets and ordered layered structure. The LDH nanoplatelets have a thickness of about $0.9 \mathrm{~nm}$ and a diameter of about $70 \mathrm{~nm}$. The diameter is much smaller than visible light wavelength. Thus, the LDH is free from light scattering, make them acceptable for a variety of optical applications. ${ }^{61,62}$ The nacrelike layered structure also help to decrease light scattering between the nanoplatelets, which was demonstrated in nacremimetic montmorillonite/polymer hybrid films. ${ }^{15,21,48}$

\section{Conclusions}

Inspired by the relationship between structure and mechanical property of natural nacre, we prepared LDH/ALG-Ca ${ }^{2+}$ hybrid film by filtrating $\mathrm{LDH} / \mathrm{ALG}^{-\mathrm{Ca}^{2+}}$ hybrid building blocks. The 
effect of the content of small-size LDH and ionic crosslinking of ALG by $\mathrm{Ca}^{2+}$ on the microstructure and interfacial interaction of LDH/ALG-Ca ${ }^{2+}$ hybrid films was studied. It was demonstrated that the cooperation of ionic crosslinking of ALG by $\mathrm{Ca}^{2+}$, interfacial hydrogen bonds between LDH and ALG, and alignment arrangement of LDH enable the nacre-mimetic hybrid film to posses a high strength of $194 \mathrm{MPa}$ and good flexibility. Furthermore, the hybrid film exhibit high transparency of 70$94 \%$ in visible light range. We believe that these results offers an innovative insight into design and preparation of high performance bio-mimetic layered materials with high transparency for practical application.

\section{Acknowledgements}

This work was supported by the National Natural Science Foundation of China (51403008), 111 Project (B14009) and China Scholarship Council.

\section{Notes and references}

1 A. P. Jackson, J. F. V. Vincent and R. M. Turner, Proc. R. Soc. London, Ser. A, 1986, 234, 415-440.

2 G. Mayer, Science, 2005, 310, 1144-1147.

3 B. L. Smith, T. E. Schäffer, M. Viani, J. B. Thompson, N. A. Frederick, J. Kindt, A. Belcher, G. D. Stucky, D. E. Morse and P. K. Hansma, Nature, 1999, 399, 761-763.

4 H. D. Espinosa, J. E. Rim, F. Barthelat and M. J. Buehler, Prog. Mater. Sci., 2009, 54, 1059-1100.

5 F. Barthelat, H. Tang, P. D. Zavattieri, C. M. Li and H. D. Espinosa, J. Mech. Phys. Solids, 2007, 55, 306-337.

6 G. E. Padhwer and N. Beecher, Polym. Eng. Sci., 1970, 10, 185192.

7 R. Z. Wang, Z. Suo, A. G. Evans, N. Yao and I. A. Aksay, J. Mater. Res., 2001, 16, 2485-2493.

8 J. Y. Sun and B. Bhushan, RSC Adv., 2012, 2, 7617-7632.

9 J. Wang, Q. Cheng and Z. Tang, Chem. Soc. Rev., 2012, 41, 1111-1129.

10 H. B. Yao, J. Ge, L. B. Mao, Y. X. Yan and S. H. Yu, Adv. Mater., 2014, 26, 163-188.

11 Q. Cheng, L. Jiang and Z. Tang, Acc. Chem. Res., 2014, 47, 1256-1266.

12 S. Wan, J. Peng, L. Jiang and Q. Cheng, Adv. Mater., 2016, 28, 7862-7898.

13 P. Podsiadlo, A. K. Kaushik, E. M. Arruda, A. M. Waas, B. S. Shim, J. D. Xu, H. Nandivada, B. G. Pumplin, J. Lahann, A. Ramamoorthy and N. A. Kotov, Science, 2007, 318, 80-83.

14 Z. Tang, N. A. Kotov, S. Magonov and B. Ozturk, Nat. Mater., 2003, 2, 413-418.

15 J. F. Wang, Q. F. Cheng, L. Lin and L. Jiang, ACS Nano, 2014, 8, 2739-2745.

16 J. Wang, Q. Cheng, L. Lin, L. Chen and L. Jiang, Nanoscale, 2013, 5, 6356-6362.

17 B. L. Liang, H. W. Zhao, Q. Zhang, Y. Z. Fan, Y. H. Yue, P. G. Yin and L. Guo, ACS Appl. Mater. Interfaces, 2016, 8, 28816-28823.
18 T. Verho, M. Karesoja, P. Das, L. Martikainen, R. Lund, A. Alegria, A. Walther and O. Ikkala, Adv. Mater., 2013, 25, 5055-5059.

19 B. L. Zhu, N. Jasinski, A. Benitez, M. Noack, D. Park, A. S. Goldmann, C. Barner-Kowollik and A. Walther, Angew. Chem., Int. Ed., 2015, 54, 8653-8657.

20 P. Das, J.-M. Malho, K. Rahimi, F. H. Schacher, B. Wang, D. E. Demco and A. Walther, Nat. Commun., 2015, 6, 5967.

21 H.-B. Yao, Z.-H. Tan, H.-Y. Fang and S.-H. Yu, Angew. Chem., Int. Ed., 2010, 49, 10127-10131.

22 Y. Y. Zhang, Y. C. Li, P. Ming, Q. Zhang, T. X. Liu, L. Jiang and Q. F. Cheng, Adv. Mater., 2016, 28, 2834-2839.

23 S. Gong, L. Jiang and Q. Cheng, J. Mater. Chem. A, 2016, 4, 17073-17079.

24 Q. Cheng, M. Wu, M. Li, L. Jiang and Z. Tang, Angew. Chem., Int. Ed., 2013, 52, 3750-3755.

25 M. Zhang, L. Huang, J. Chen, C. Li and G. Q. Shi, Adv. Mater., 2014, 26, 7588-7592.

26 L. Huang, C. Li, W. Yuan and G. Shi, Nanoscale, 2013, 5, 3780-3786.

27 Y. Q. Li, T. Yu, T. Y. Yang, L. X. Zheng and K. Liao, Adv. Mater., 2012, 24, 3426-3431.

28 L. Q. Liu, Y. Gao, Q. Liu, J. Kuang, D. Zhou, S. T. Ju, B. H. Han and Z. Zhang, Small, 2013, 9, 2466-2472.

29 J. Wang, J. Qiao, J. Wang, Y. Zhu and L. Jiang, ACS Appl. Mater. Interfaces, 2015, 7, 9281-9286.

30 L. J. Bonderer, A. R. Studart and L. J. Gauckler, Science, 2008, 319, 1069-1073.

31 E. Munch, M. E. Launey, D. H. Alsem, E. Saiz, A. P. Tomsia and R. O. Ritchie, Science, 2008, 322, 1516-1520.

32 H. Zhao, Y. Yue, L. Guo, J. Wu, Y. Zhang, X. Li, S. Mao and X. Han, Adv. Mater., 2016, 28, 5099-5105.

33 L. J. Bonderer, A. R. Studart, J. Woltersdorf, E. Pippel and L. J. Gauckler, J. Mater. Res., 2009, 24, 2741-2754.

34 Y. Q. Shu, P. G. Yin, B. L. Liang, H. Wang and L. Guo, ACS Appl. Mater. Interfaces, 2014, 6, 15154-15161.

35 P. Podsiadlo, Z. Tang, B. S. Shim and N. A. Kotov, Nano Lett., 2007, 7, 1224-1231.

36 S. J. Wan, J. S. Peng, Y. C. Li, H. Hu, L. Jiang and Q. F. Cheng, ACS Nano, 2015, 9, 9830-9836.

37 R. Libanori, F. H. L. Munch, D. M. Montenegro and A. R. Studart, Compos. Sci. Technol., 2012, 72, 435-445.

38 L. J. Bonderer, K. Feldman and L. J. Gauckler, Compos. Sci. Technol., 2010, 70, 1966-1972.

39 H. Sehaqui, J. Kochumalayil, A. D. Liu, T. Zimmermann and L. A. Berglund, ACS Appl. Mater. Interfaces, 2013, 5, 76137620.

40 A. Liu, A. Walther, O. Ikkala, L. Belova and L. A. Berglund, Biomacromolecules, 2011, 12, 633-641.

41 Y. Q. Shu, P. G. Yin, B. L. Liang, S. S. Wang, L. C. Gao, H. Wang and L. Guo, J. Mater. Chem., 2012, 22, 21667-21672.

42 S. Deville, E. Saiz, R. K. Nalla and A. P. Tomsia, Science, 2006, 311, 515-518.

43 L.-B. Mao, H.-L. Gao, H.-B. Yao, L. Liu, H. Cölfen, G. Liu, S.-M. Chen, S.-K. Li, Y.-X. Yan, Y.-Y. Liu and S.-H. Yu, Science, 2016, 354, 107-110. 
44 P. Ming, Z. F. Song, S. S. Gong, Y. Y. Zhang, J. L. Duan, Q. Zhang, L. Jiang and Q. F. Cheng, J. Mater. Chem. A, 2015, 3, 21194-21200.

45 B. Long, C.-A. Wang, W. Lin, Y. Huang and J. Sun, Compos. Sci. Technol., 2007, 67, 2770-2774.

46 W. Lin, C.-a. Wang, H. Le, B. Long and Y. Huang, Mater. Sci. Eng., C, 2008, 28, 1031-1037.

47 J. F. Wang, L. Lin, Q. F. Cheng and L. Jiang, Angew. Chem., Int. Ed., 2012, 51, 4676-4680.

48 A. Walther, I. Bjurhager, J.-M. Malho, J. Pere, J. Ruokolainen, L. A. Berglund and O. Ikkala, Nano Lett., 2010, 10, 2742-2748.

49 A. Walther, I. Bjurhager, J.-M. Malho, J. Ruokolainen, L. Berglund and O. Ikkala, Angew. Chem., Int. Ed., 2010, 49, 6448-6453.

50 P. Podsiadlo, A. K. Kaushik, B. S. Shim, A. Agarwal, Z. Tang, A. M. Waas, E. M. Arruda and N. A. Kotov, J. Phys. Chem. B, 2008, 112, 14359-14363.

51 P. Podsiadlo, Z. Q. Liu, D. Paterson, P. B. Messersmith and N. A. Kotov, Adv. Mater., 2007, 19, 949-955.

52 H. Zhu, Q. Zhang and S. P. Zhu, ACS Appl. Mater. Interfaces, 2016, 8, 17395-17401.
53 C. Menakbi, F. Quignard and T. Mineva, J. Phys. Chem. B, 2016, 120, 3615-3623.

54 J. Y. Sun, X. H. Zhao, W. R. K. Illeperuma, O. Chaudhuri, K. H. Oh, D. J. Mooney, J. J. Vlassak and Z. G. Suo, Nature, 2012, 489, 133-136.

55 Y. A. Morch, I. Donati, B. L. Strand and G. Skjak-Braek, Biomacromolecules, 2006, 7, 1471-1480.

56 Y. Q. Shu, P. G. Yin, J. F. Wang, B. L. Liang, H. Wang and L. Guo, Ind. Eng. Chem. Res., 2014, 53, 3820-3826.

57 G. L. Du, F. X. Wu, Y. Cong, L. Nie, S. H. Liu, G. R. Gao and J. Fu, Chem. Commun., 2015, 51, 15534-15537.

58 S. J. Wan, H. Hu, J. S. Peng, Y. C. Li, Y. Z. Fan, L. Jiang and Q. F. Cheng, Nanoscale, 2016, 8, 5649-5656.

59 S. Park, K.-S. Lee, G. Bozoklu, W. Cai, S. T. Nguyen and R. S. Ruoff, ACS Nano, 2008, 2, 572-578.

60 Y. Zhuang, F. Yu, H. Chen, J. Zheng, J. Ma and J. Chen, J. Mater. Chem. A, 2016, 4, 10885-10892.

61 M. Nogi, S. Iwamoto, A. N. Nakagaito and H. Yano, Adv. Mater., 2009, 21, 1595-1598.

62 H. Yano, J. Sugiyama, A. N. Nakagaito, M. Nogi, T. Matsuura, M. Hikita and K. Handa, Adv. Mater., 2005, 17, 153-155. 